\title{
Methodological approach to grain yield planning
}

\author{
Olga Makarova ${ }^{1}$,Valentin Makarov ${ }^{2, *}$, Svetlana Gasparyan ${ }^{1}$, Zhanna Napris ${ }^{1}$, and \\ Alexander Shemyakin ${ }^{2}$ \\ ${ }^{1}$ Academy of Law and Management of the Federal Penitentiary Service of Russia, 1, Sennaya str., \\ 390000, Ryazan, Russia \\ ${ }^{2}$ Ryazan State Agrotechnological University by P.A. Kostycheva, 1, Kostycheva str., 390044, \\ Ryazan, Russia
}

\begin{abstract}
The global problems of mankind, especially in recent decades, have an increasing impact on the agrarian sphere of activity of any country, including Russia. In modern conditions, the strategic goals outlined for increasing the productivity and sustainability of agricultural production in the agricultural sector of the country should be solved comprehensively within the framework of adaptive landscape farming, taking into account specific soil-climatic, organizational, economic, environmental and other factors. The concept of "maximum possible grain yield" will always change upward with increasing intensification of agriculture, maintaining soil fertility, creating and introducing highly productive varieties, using a mineral nutrition system, as well as means of protection against pests and diseases, etc. The article establishes the conditions under which it is necessary to focus on obtaining the planned yield, the dependence of the possible yield on the utilization factor of photosynthetic activity and radiation for the growing season is provided. Based on the determination of the yield, a set of measures and techniques is developed to obtain a planned crop and an organization chart is proposed on the problem of planning grains. According to the results of the research, the dependence of the crop cost on the level of optimal planning is provided.
\end{abstract}

\section{Introduction}

In connection with the rapid technological development of society in agricultural production, the indicator «maximum possible grain yield» will constantly change in the direction of its increase. In this regard, scientists from different countries are looking for approaches, methods and tools to improve the crop sector of agriculture to increase the food supply of our states [1-15]. Therefore, there is a need for planning crops, which consists in developing a set of measures for timely and high-quality implementation, which is ensured by obtaining the maximum possible planned yield.

It is advisable to carry out crop planning in two directions. The first one is its planning when grains growing is based on a compilation of information during the growing season,

${ }^{*}$ Corresponding author: va_makarov@rambler.ru 
soil-biological and agrometeorological indicators of the region in which the crop is cultivated. The second one is obtaining a planned yield, taking into account detailed in space and time characteristics of the soil, vegetation and microclimate, as well as creating simulation models of soil fertility and crop productivity in the formation of grain crops.

Yield planning and the implementation of agricultural measures to obtain it are possible under the following conditions:

- determining the theoretically possible value of the yield by photo synthetically active radiation (PhAR) and its use by crops;

- determining the yield size by bioclimatic indicators of the region, allowing to proceed to the estimation of the possible productivity of agricultural land;

- carrying out theoretically possible calculations of the crop size by the moisture supply;

- determining the yield size by photo synthetic potential of crops;

- creating a fertilizer application system taking into account soil humus and plant nutrient requirements to obtain the planned yield;

- developing a set of agrotechnical measures for each grain variety aimed at obtaining the possible yield;

- taking into account and the correct application of the main provisions and patterns occurring in the system of agriculture and crop production, respectively;

- developing specific measures to combat diseases and pests of crops during their cultivation.

\section{Materials and methods}

An integral part of environmental studies is the analysis of methods for evaluating the crop productivity. The work of J. Azzi (1959) can be attributed to works first examined the modeling of agro climatic resources in relation to specific crops.

One of the simplest models of ground-based dry matter mass accumulation depending on moisture availability was proposed by de Wit (1976). For areas with limited moisture and sufficient heat, the model has the following form:

$$
P_{C}=\frac{f \cdot T_{r}}{E e P}
$$

where: $\mathrm{P}_{\mathrm{c}}$ is the ground dry matter mass;

$\mathrm{f}$ is an empirical coefficient characterizing the biological characteristics of the crop;

$\mathrm{T}_{\mathrm{r}}$ is actual transpiration of crops, which is an indicator of moisture availability;

$\mathrm{E}_{\mathrm{eP}}$ is potential evapotranspiration (potential total evaporation inherent in a given plant community for specific conditions).

However, despite the apparent simplicity of the model, it is practically difficult to use it because of the need to calculate indicator $f$ and the difficulty of obtaining indicators of evapotranspiration.

To implement the indicated directions, a methodological approach to obtaining possible yields according to various indicators characterizing the state of the environment in each particular region can be proposed.

The maximum possible value of the obtained grain yield can be determined by the following equation:

$$
\mathrm{Y}=\frac{\mathrm{K}_{\mathrm{PhAR}} \cdot \mathrm{G}_{\mathrm{PhAR}}}{100 \mathrm{C}},
$$

where: $\mathrm{Y}$ is the maximum possible yield on dry biomass of crops, $(\mathrm{dt} / \mathrm{ha})$;

$\mathrm{K}_{\mathrm{PhAR}}$ is the coefficient of the crop's use of photo synthetically active radiation, (\%); 
$\mathrm{G}_{\mathrm{PhAR}}$ is photo synthetically active radiation for the vegetation period, (kcal/ha);

$\mathrm{C}$ is the calorific value of a unit of yield of organic matter $(\mathrm{kcal} / \mathrm{kg})$.

\section{Results and discussion}

Thus, knowing the photo synthetically active radiation amount, it is possible to set the task to accumulate by crops at least $2-3 \%$. Then, taking into account factors and based on this indicator, the possible yield during the growing season is determined.

An integral estimation of the productivity of climatic and soil conditions was proposed by D.I. Shashko.

Estimation of the biological productivity of the soil according to this method is carried out by the indicator of bioclimatic potential (BCP) according to the following equation:

$$
\mathrm{BCP}=\mathrm{K}_{\mathrm{P}} \frac{\sum \mathrm{t}>10^{\circ}}{1000^{\circ}},
$$

where: $K_{P}$ is the biological productivity coefficient, which is the ratio of maximum productivity when sufficient moisture to productivity with a lack of moisture (vibration limits: 1.0 for a humid forest zone);

$\sum \mathrm{t}>10^{\circ}$ is the sum of daily average air temperatures higher than $10^{\circ} \mathrm{C}$ in the vegetation period;

$1000^{\circ}$ is the sum of daily average air temperatures higher than $10^{\circ} \mathrm{C}$ on the northern border of agriculture.

The climatic potential in each region under conditions of sufficient humidity is approximately equal to 0.001 of the sum of air temperatures above $10^{\circ} \mathrm{C}$.

Having determined the bioclimatic potential, it is possible to calculate the value of the possible yield (y, dt/ha) according to the formula:

$$
\mathrm{y}=\alpha \cdot \mathrm{BCP},
$$

It was experimentally determined that when using $1 \%$ PhAR of plants it was approximately $10 \mathrm{dt}$ and when $2 \% \mathrm{PhAR}$ it was $20 \mathrm{dt}$.

To determine the possible productivity of phytomass, one can apply the formula of A.M. Ryabchikov:

$$
\mathrm{K}_{\mathrm{pl}}=\frac{\mathrm{W} \cdot \mathrm{T}_{\mathrm{v}}}{36 \mathrm{R}}
$$

where: $\mathrm{K}_{\mathrm{pL}}$ is the bio hydrothermal potential of grain productivity, points;

$\mathrm{W}$ is reserves of productive moisture in a meter layer of soil, $\mathrm{mm}$;

$\mathrm{T}_{\mathrm{v}}$ is the duration of the growing season, decades;

36 is the number of decades during the growing season;

$\mathrm{R}$ is the average annual rational balance, the amount of PhAR for the growing season, $\left(\mathrm{kcal} / \mathrm{cm}^{2}\right.$ a year).

This formula includes a rational balance of sowing, which has a direct effect on the evaporation of water from the surface of the soil and plants.

Then the value of the biological mass for grain crops under the prevailing cultivation conditions can be determined by the formula:

$$
\mathrm{M}=\beta \cdot \mathrm{K}_{\mathrm{pl}},
$$

where: $\mathrm{M}$ is possible biomass yield ( $\mathrm{dt} / \mathrm{ha}$ );

$\beta$ is a coefficient of approximately $20 \mathrm{dt} / \mathrm{ha}$. 
To determine the value of the possible yield according to the prevailing average longterm moisture supply, it is necessary to use the following formula:

$$
\mathrm{Y}=\mathrm{B}_{\mathrm{s}} \cdot \mathrm{P}_{\mathrm{ss}} \cdot \mathrm{K}
$$

where: $\mathrm{B}_{\mathrm{s}}$ is soil bonitet score;

$\mathrm{P}_{\mathrm{ss}}$ is crop price of the soil score, determined for the specific conditions of the zone, by statistical analysis of yield data, $\mathrm{kg} / \mathrm{ha}$;

$\mathrm{K}$ is the correction factor for agrochemical soil properties.

After calculating the predicted yield of grain crops, it is necessary to develop a set of methods for cultivating them. One of the main roles in this set of measures belongs to the justification of doses of mineral fertilizers for a planned yield.

When planning the yield, the calculation of doses of mineral fertilizers should be carried out by various methods (it is necessary to apply at least 2-3 methods).

In all cases, when developing an optimal grain nutrition system, it is necessary to take into account:

- provision of soil with easy hydrolysable nitrogen, as well as available forms of phosphorus and potassium;

- the chemical composition of the main product;

- the removal of nutrients by the total yield per 1 centner of the main product;

- soil nutrient utilization rate (NPK) of organic and mineral fertilizers;

- terms and methods of fertilizer application;

- payback of fertilizers (output in dt of the main product per $1 \mathrm{dt}$ of fertilizers (NPK).

By setting these indicators, one can determine the dose of the fertilizer using the following formula:

$$
\mathrm{D}=\frac{100 \mathrm{R}-\mathrm{SC}_{\mathrm{s}}}{\mathrm{C}_{\mathrm{f}}}
$$

where: $\mathrm{D}$ is the fertilizer dose, $(\mathrm{kg} / \mathrm{ha})$;

$\mathrm{R}$ is crop nutrient removal, $(\mathrm{kg} / \mathrm{ha})$;

$\mathrm{S}$ is the stock of available nutrients in the soil, $(\mathrm{kg} / \mathrm{ha})$;

$\mathrm{Cs}$ is the soil nutrient utilization coefficient, (\%);

$\mathrm{C}_{\mathrm{f}}$ is the soil fertilizer nutrient utilization rate, $(\%)$;

Currently, a number of methods are used when calculating fertilizer doses for a planned yield, but all of them are based on the balance method with statistical justification of the proposed methods. The complex method based on a point assessment of soil properties, determining the value of an appraising point and the return on fertilizer yield. In this case, the calculation is based on the planned yield increase.

The main one is the balance method. According to this method, the fertilizer rate is determined for each nutrient element: the removal of this element by the crop, the coefficient of the nutrient use from fertilizers, its content in the soil and the coefficient of this element use from the soil are taken into account according to the formula:

$$
\mathrm{D}_{\mathrm{AS}}=\frac{\left(\mathrm{y} \cdot \mathrm{R}_{1}\right)-\left(\mathrm{P} \cdot \mathrm{C}_{\mathrm{c}} \cdot \mathrm{C}_{\mathrm{S}}\right)}{\mathrm{C}_{\mathrm{f}}},
$$

where: $\mathrm{D}_{\mathrm{AS}}$ is the dose of nitrogen, phosphorus, or potassium per planned yield, $\mathrm{kg} / \mathrm{ha}$;

$\mathrm{R}_{1}$ is removal of NRK from $1 \mathrm{dt}$. of the main and the corresponding amount of by-products, $\mathrm{kg}$;

$\mathrm{P}$ is NRK content in soil, $\mathrm{mg} / 100 \mathrm{~g}$;

$\mathrm{C}_{\mathrm{c}}$ is conversion coefficient from $\mathrm{mg} / 100$ to $\mathrm{kg} / \mathrm{ha}$; 
Its average values for soil layers $0-22 \mathrm{~cm}$ are $30 \mathrm{~kg} / \mathrm{ha}$, those of $0-25 \mathrm{~cm}$ are $34 \mathrm{~kg} / \mathrm{ha}$, those of $0-28 \mathrm{~cm}$ are $38 \mathrm{~kg} / \mathrm{ha}$ ad those of $0-30 \mathrm{~cm}$ are $41 \mathrm{~kg} / \mathrm{ha}$.

$\mathrm{C}_{\mathrm{s}}$ is soil nutrient utilization coefficient;

$\mathrm{C}_{\mathrm{f}}$ is fertilizer nutrient utilization coefficient.

If manure is introduced $(10,11)$, then the formula takes the following form:

$$
\mathrm{D}_{\mathrm{AS}}=\frac{\left(\mathrm{Y} \cdot \mathrm{V}_{1}\right)-\left(\mathrm{P} \cdot \mathrm{C}_{\mathrm{c}} \cdot \mathrm{C}_{\mathrm{S}}\right)+\left(\mathrm{D}_{\mathrm{m}} \cdot \mathrm{N}_{\mathrm{m}} \cdot \mathrm{C}_{\mathrm{m}}\right)}{\mathrm{C}_{\mathrm{f}}},
$$

where: $\mathrm{D}_{\mathrm{m}}$ is the amount of manure introduced per 1 ha in tons;

$\mathrm{N}_{\mathrm{m}}$ is nutrient content in 1 ton of manure in kilograms;

$\mathrm{C}_{\mathrm{m}}$ is nutrition utilization from manure coefficient.

The calculation is carried out according to the following logical scheme. The following things are determined:

1) NPK removal with the crop $R_{\text {total }}=Y \cdot R_{1}$;

2) soil nutrient content $P \cdot C_{c}$;

3) possible use of soil nutrients $\mathrm{P} \cdot \mathrm{C}_{\mathrm{c}} \cdot \mathrm{C}_{\mathrm{s}}-\mathrm{R}_{\mathrm{s}}$;

4) nutrients introduced with manure $D_{m} \cdot C_{m}$;

5) removal of nutrients from manure $R_{m}=D_{m} \cdot N_{m} \cdot C_{m}$;

6) the total removal from manure and soil will be $R_{y}+R_{s}$;

7) it's necessary to bring with fertilizers $R_{y}=R_{\text {total }}-\left(R_{m}+R_{s}\right)$;

8) it's necessary to bring with fertilizers $D_{A S}=\frac{R_{y}}{C_{y}}$.

The general principle of organizing research on planning grain yields can be explained by a functional diagram for solving the problem presented in Figure 1.

The functional diagram (Fig. 1) provides for research in the field of soil physics, hydro physics, plant physiology and the theory of biogeocenosis, as well as applied research on the study of water, heat, food regimes, as well as photosynthesis and respiration, chemical and biological processes in the soil, diseases and pests.

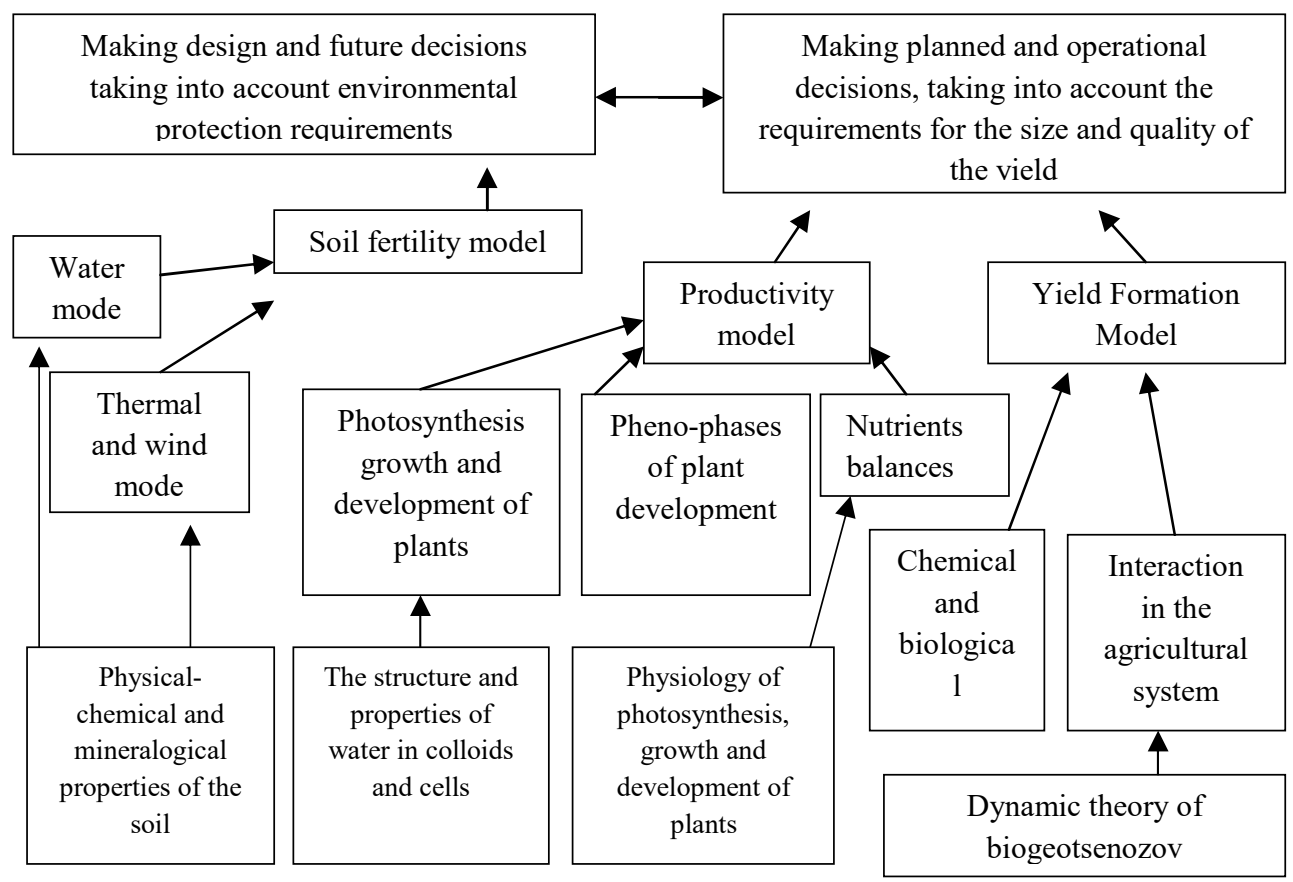

Fig. 1. Functional diagram of the organization on the problem of planning the crop yield. 
The above processes establish a quantitative relationship between the level of the planned yield and statistical characteristics of the expected yield. To determine the specific level of grain yield from a position of economic efficiency, the resulting net income is determined as it follows:

$$
\mathrm{u}=\mathrm{C}_{\mathrm{y}} \mathrm{Y}-\mathrm{C}_{\mathrm{T}}\left(\mathrm{Y}_{\mathrm{PlY}}\right)
$$

where: $\mathrm{C}_{\mathrm{y}}$ is the cost of a unit of grain yield, rub;

$\mathrm{C}_{\mathrm{T}}$ is technological costs necessary (therefore, planned) to obtain some planned grain yield $\mathrm{Y}_{\mathrm{Pl} \mathrm{Y}}$, rub;

$\mathrm{Y}$ is grain yield, $\mathrm{dt}$.

It follows that if $\mathrm{Y}$ were known in advance, each time it would be possible to choose such planned technological costs $\mathrm{Y}_{\mathrm{Pl} \mathrm{Y}}$, that would ensure the maximum profit.

However, due to poor predictability and variability of weather conditions for any choice of $\mathrm{Y}_{\mathrm{Pl} \mathrm{Y}}$, yield $\mathrm{Y}$ will be random and therefore optimal $\mathrm{Y}_{\mathrm{Pl}} \mathrm{Y}$ should be understood only in the sense of predicting the best average results.Based on this, the choice of a level of the planned grain yield that ensures the achievement of the maximum average income can be considered the climatologically optimal strategy. It can be represented as it follows:

$$
\mathrm{u}=\mathrm{C}_{\mathrm{y}} \overline{\mathrm{Y}}_{\mathrm{oy}}-\mathrm{C}_{\mathrm{T}}\left(\mathrm{Y}_{\mathrm{PlY}}\right)
$$

where: $\bar{Y}_{\text {oy }}$ is the planned yield, $t$; and optimum $\mathrm{Y}_{\operatorname{Pr} \mathrm{Y}}$ meets the equality:

$$
\frac{\partial \mathrm{Y}_{\mathrm{oy}}}{\partial \mathrm{Y}_{\mathrm{P}_{\mathrm{i}} \mathrm{Y}}}=\frac{1}{\mathrm{C}_{\mathrm{y}}} \times \frac{\partial C_{T}\left(\mathrm{Y}_{\mathrm{PlY}}\right)}{\partial \mathrm{Y}_{\mathrm{P}_{\mathrm{i}} \mathrm{Y}}},
$$

We concretize the latter dependence under the assumption that technological costs increase in proportion to the chosen level of the planned yield, i.e.

$$
\mathrm{C}_{\mathrm{T}}\left(\mathrm{Y}_{\mathrm{PlY}}\right)=\mathrm{a}+\mathrm{bY} \mathrm{PIY}_{\mathrm{Y}}
$$

where: $\mathrm{a}$ and $\mathrm{b}$ are some coefficients.

Then for the case of the normal distribution of the really possible yield one gets:

$$
\mathrm{F}\left(\mathrm{Y}_{\mathrm{PlY}}\right)=\frac{1}{2}-\frac{\mathrm{b}}{\mathrm{C}_{\mathrm{Y}}(1-\varepsilon)},
$$

where: $\mathrm{F}$ is the probability integral.

Let us analyze this result. The problem has a solution when $\frac{b}{C_{Y}(1-\varepsilon)}<1$, and optimal value $\mathrm{Y}_{\mathrm{Pl} \mathrm{Y}}$ turns out to be positive for $\frac{\mathrm{b}}{\mathrm{C}_{\mathrm{Y}}(1-\varepsilon)}<\frac{1}{2}$ and negative for $\frac{\mathrm{b}}{\mathrm{C}_{\mathrm{Y}}(1-\varepsilon)}>\frac{1}{2}$.

In accordance with this, the optimal economic strategy in the first case is the choice of the level of the planned crop that exceeds the average value of the really possible crop, and in the second case - vice versa.

If the actual really possible yield turned out to be lower than the planned one, then the funds spent on the estimated yield are partially spent unintentionally, since yields above the really possible yield are rarely possible in principle. The resulting losses are $\Delta \mathrm{u}=\mathrm{b}\left(\mathrm{Y}_{\mathrm{PIY}}-\right.$ $\left.\mathrm{Y}_{\mathrm{ROY}}\right)$. On the other hand, if the really obtained yield is higher than the planned one, then as a result of the limiting influence of agricultural technology oriented towards lower productivity, a part of the potential yield $\Delta y=(1-\varepsilon)\left(\mathrm{Y}_{\mathrm{ROY}}-\mathrm{Y}_{\mathrm{PlY}}\right)$ is lost, and the resulting losses are defined as $\Delta \mathrm{u}=\mathrm{C}_{\mathrm{y}}(1-\varepsilon)\left(\mathrm{Y}_{\mathrm{ROY}}-\mathrm{Y}_{\mathrm{PlY}}\right)$.

The union of the two equations gives: 


$$
\Delta u= \begin{cases}{ }^{b}\left(Y_{P I y}-Y_{R O Y}\right) & \text { when } Y_{R O Y} \leq Y_{P l y} \\ {\left[C_{y}(1-\varepsilon)-b\right]\left(Y_{P l y}-Y_{R O Y}\right)} & \text { when } Y_{R O Y}>Y_{P l y}\end{cases}
$$

The optimal level of the planned crop, at which average losses $\Delta \overline{\mathrm{u}}$ are minimal, is found from the equation:

$$
\mathrm{F}\left(\mathrm{Y}_{\mathrm{Pl} \mathrm{y}}\right)=\frac{1}{2} \frac{1-\mathrm{k}}{1+\mathrm{K}}
$$

where: $\mathrm{k}=\frac{\mathrm{b}}{\mathrm{C}_{\mathrm{y}}(1-\varepsilon)-\mathrm{b}}$.

The numerical values of optimal $\mathrm{Y}_{\mathrm{Pl} \text { y }}$ are presented in Table 1.

Table 1. The optimum planned grain yield.

\begin{tabular}{|c|c|c|c|c|c|c|c|c|c|c|c|}
\hline $\mathrm{k}$ & $1 / 20$ & $1 / 10$ & $1 / 5$ & $1 / 3$ & $1 / 2$ & 0 & 2 & 3 & 4 & 10 & 20 \\
\hline $\mathrm{Y}_{\mathrm{Pl} \mathrm{Y}}$ & 1.67 & 1.34 & 0.97 & 0.63 & 0.43 & 0 & -0.43 & -0.67 & -0.97 & -1.34 & -1.67 \\
\hline
\end{tabular}

The considered linear model is not universal, of course. In particular, there is a reason to believe that with increasing yields, the costs of obtaining them will increase not according to the linear law, but faster.

In support of this, one can refer to the data of sources, according to which the increase in the yield of grain crops from 20 to $40 \mathrm{~kg} / \mathrm{ha}$, i.e. twice, increases the energy consumption of fossil fuels by more than 10 times.

Given this, one takes for $\mathrm{C}_{\mathrm{T}}\left(\mathrm{Y}_{\mathrm{Pl} \mathrm{Y}}^{2}\right)$ a quadratic approximation of the following form:

$$
\mathrm{C}_{\mathrm{T}}\left(\mathrm{Y}_{\mathrm{Ply}}\right)=\mathrm{m}+1 \mathrm{Y}_{\mathrm{Ply}}^{2},
$$

where: $\mathrm{m}$ and $\mathrm{l}$ are constant coefficients.

After simple transformations one gets:

$$
\mathrm{F}\left(\mathrm{Y}_{\mathrm{Pl}}\right)=\frac{1}{2}-\frac{21 \mathrm{Y}_{\mathrm{ROY}}}{(1-\varepsilon) \mathrm{C}_{\mathrm{y}}}\left(\mathrm{Y}_{\mathrm{PlY}}+\frac{\mathrm{Y}_{\mathrm{ROY}}}{\sigma_{\mathrm{ROY}}}\right)
$$

It is easy to verify that equation (14) always has a unique solution. Moreover, when $\mathrm{l} \frac{\mathrm{Y}_{\mathrm{ROY}}}{\mathrm{l}(1-\varepsilon) \mathrm{C}_{\mathrm{y}}}<\frac{1}{4}$, figure 1 is positive and negative when $\mathrm{IY}_{\mathrm{ROY}} /(\mathrm{l}-\varepsilon) \mathrm{C}_{\mathrm{y}}>\frac{1}{4}$. In accordance with this, in the first case, it is advisable to take the yield above the average value of the really possible grain yield, and in the second case, below it, which will affect the maximum income from the obtained yield.

\section{Conclusion}

1. With the development of scientific and technological progress, the value of the limit of possible productivity changes in the direction of constant increase.

2. It is recommended to plan the yield in two directions: directly during the cultivation of crops (by observation) and taking into account regional soil and climatic conditions.

3. When planning the yield, it is necessary to justify the dose of fertilizer application correctly. Therefore, the article considers a number of methods that allow calculating the applied optimal doses of fertilizers used.

4. Areas of science whose functional studies are capable of affecting the establishment of a more accurate indicator of a promising grain yield are identified.

5. Economic and mathematical relationships are given that make it possible to program grain yields based on the bioclimatic potential of any region of Russia. 


\section{References}

1. Ling Zhang, Zheng-yuan Liang, Xiao-ming He and others, Field Crops Research 249, (2020) doi: 10.1016/j.fcr.2020.107754

2. D. Beillouin, R. Trépos, A. Gauffreteau, M-H. Jeuffroy, European Journal of Agronomy 101, 174-182 (2018) doi:10.1016/j.eja.2018.09.001

3. A. Kubo, J.-M. Albina, Y. Umeno, Polymer 17726, $84-90$ (2019) doi:10.1016/j.polymer.2019.05.045

4. N. Byshov, V. Makarov, O. Makarova, S. Gasparyan, Z. Novozhilova, IOP Conference Series: Earth and Environmental Science 403(1), (2019) doi: 10.1088/17551315/403/1/012097

5. Q. Yang, L. Shi, J. Han, Y. Zha, P. Zhu, Field Crops Research 2351, 142-153 (2019) doi:10.1016/j.fcr.2019.02.022

6. W. Kuang, G.S. Was, Acta Materialia 1821, 120-130 (2020) doi:10.1016/j.actamat.2019.10.041

7. A. Hidayatullah, Rice Science 23, 326-333 (2016) doi:10.1016/j.rsci.2016.02.007

8. L. Bolzoni, N. Hari Babu, Journal of Materials Research and Technology 8, 5631-5638 (2019) doi: 10.1016/j.jmrt.2019.09.031

9. Suwei Feng, Shubo Gu, Hongbo Zhang, Dong Wang, Field Crops Research 214, 131141 (2017) doi: 10.1016/j.fcr.2017.08.007

10. C. Zhang, J. Liu, J. Shang, H. Cai, Science of The Total Environment 631-632, 677687 (2018) doi: 10.1016/j.scitotenv.2018.03.004

11. Yun-fei Hu, Fei You, Qi-you Luo, Food Policy 79, 224-234 (2018) doi: 10.1016/j.foodpol.2018.07.007

12. M. Jiang, B. Devincre, G. Monnet, International Journal of Plasticity 113, 111-124 (2019) doi: 10.1016/j.ijplas.2018.09.008

13. H. Hattori, T. Mitsunaga, D.L.J. Clive, Tetrahedron Letters, 60, 1989-1991 (2019) doi: 10.1016/j.tetlet.2019.06.050

14. A. Pedro, R. Savin, M.A.J. Parry, G.A. Slafer, Field Crops Research 129, 59-70 (2012) doi: 10.1016/j.fcr.2012.01.016

15. S. Hussain, A.M. Khan, Z. Rengel, Science of The Total Environment 654, 402-408 (2019) doi: 10.1016/j.scitotenv.2018.11.097 